\title{
A survey of broken rotor bar detection using PT and HT in squirrel cage electrical machine
}

\begin{abstract}
Early detection of faults in electrical machines are imperative because of their diversity of use in different fields. A suitable fault monitoring scheme helps to stop propagation of the failure or limit its escalation to severe degrees and thus prevents unscheduled downtimes that cause loss of production and financial income. In this study, a survey of methods based on the Park transform and Hilbert transform for broken rotor bar fault monitoring in Squirrel cage electrical machine is presented.
\end{abstract}

Keyword: Broken rotor bar; Hilbert transform; Motor current signature analysis; Park transform; Squirrel cage electrical machine 